MLM-MU-89-68-0005

\title{
Coordination of Engineering Applications: Project Summary
}

Patrick J. Cassidy

August 31, 1989

\author{
RECEIVED \\ JUL 221996 \\ OSTI
}

\section{MOUND}

operated by EGRE MOUND APPLIED TECHNOLOGIES

P.O. Box 3000, Miamisburg, Ohio 45343-3000

for the

U. S. DEPARTMENT OF ENERGY

Contract No. DE-AC04-88DP43495 


\section{DISCLAIMER}

This report was prepared as an account of work sponsored by an agency of the United States Government. Neither the Uniteid States Government nor any agency thereof. nor any of thelr employees. makes any warranty. express or Implled. or assumes any legal liablilty or responsibility for the accuracy. completeness. or usefulness of any information. apparatus. product. or process disclosed. or represents that its use would not Infringe privately owned rights. Reference herein to any speciflc commerclal product. process, or servlce by trade name. trademark. manufacturer. or otherwise. does not necessarlly constltute or imply its endorsement. recommendation. or favoring by the United States Government or any agency thereof. The views - and opinions of authors expressed herein do not necessarlly state or reflect those of the United States Government or any agency thereof. 


\title{
Coordination of Engineering Applications: Project Summary
}

\author{
Patrick J. Cassidy
}

Issued: August 31, 1989*

${ }^{*}$ This report was written in December 1988.

\section{MOUND}

operated by EG\&E MOUND APPLIED TECHNOLOGIES

P.O. Box 3000, Miamisburg, Ohio 45343-3000

for the

U. S. DEPARTMENT OF ENERGY

Contract No. DE-AC04-88DP43495 


\section{Contents}

Page

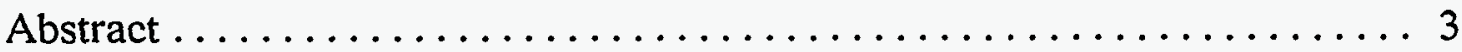

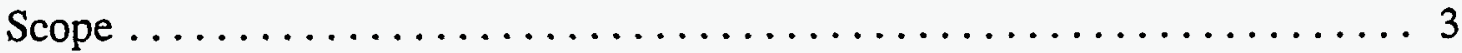

Definition of Project Deliverables $\ldots . \ldots \ldots \ldots \ldots \ldots \ldots \ldots \ldots \ldots \ldots$

Deliverable No. 1: Define and Develop Interfaces Among Subgroups ... 5

Interface A: Design Agency $\leftrightarrow$ CAD $\ldots \ldots \ldots \ldots \ldots \ldots \ldots \ldots$

Interface $\mathrm{B}: \mathrm{CAD} \leftrightarrow \mathrm{EWS} \ldots \ldots \ldots \ldots \ldots \ldots \ldots \ldots \ldots \ldots \ldots \ldots \ldots \ldots \ldots$

Interface $\mathrm{C}: \mathrm{CAD} \leftrightarrow \mathrm{CAE} \ldots \ldots \ldots \ldots \ldots \ldots \ldots \ldots \ldots \ldots \ldots \ldots$

Interface $\mathrm{D}: \mathrm{EWS} \leftrightarrow 4 \mathrm{M}$ Database $\ldots \ldots \ldots \ldots \ldots \ldots \ldots \ldots \ldots$

Interface $\mathrm{E}: \mathrm{EWS} \leftrightarrow \mathrm{CAE} \ldots \ldots \ldots \ldots \ldots \ldots \ldots \ldots \ldots \ldots \ldots \ldots \ldots \ldots$

Interface $\mathrm{F}: \quad$ EWS $\leftrightarrow$ Technical Manuals $\ldots \ldots \ldots \ldots \ldots \ldots \ldots 10$

Interface G: Technical Manuals $\rightarrow$ Shop Floor .......... 12

Deliverable No. 2: Identify and Address Selected Issues as Related to Integrating Engineering Applications Plantwide ... 13

System Incompatibilities $\ldots \ldots \ldots \ldots \ldots \ldots \ldots \ldots \ldots \ldots \ldots$

Communications Incompatibilities $\ldots \ldots \ldots \ldots \ldots \ldots \ldots \ldots \ldots \ldots$

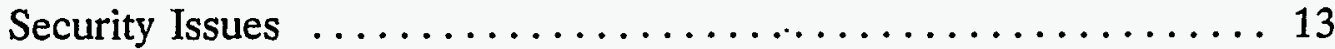

Centralized Access Control to Data .................. 16

Administrative Issues ........................... 18

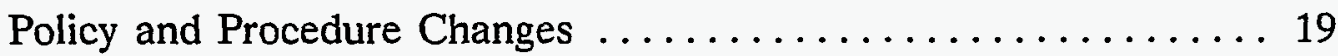

Role/Responsibility Changes ...................... 19

System Feasibility .......................... 20

Deliverable No. 3: Demonstrate Selected Capabilities for Unclassified Portions of the MC4123 and MC4098 Programs .... 20

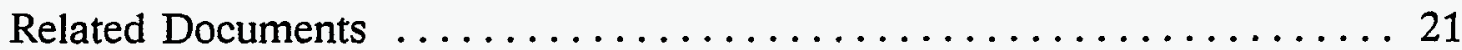

Appendix A: Computer Security Proposals $\ldots \ldots \ldots \ldots \ldots \ldots \ldots \ldots 23$

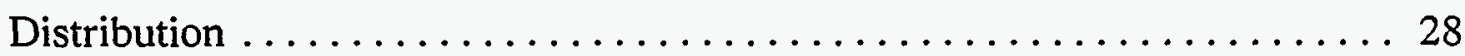




\section{Abstract}

The purpose of this project was to focus on and coordinate several active engineering applications projects to optimize their integration. The end result of the project was to develop and demonstrate the capability of electronically receiving a part from the originating design agency, performing computer-aided engineering analyses, developing process plans, adding electronic input from numerous onsite systems, and producing an online operation sheet (manual) for viewing on a shop floor workstation. A successful demonstration of these applications was performed in December 1988.

\section{Scope}

This project incorporates input from each of the following subprojects:

- Engineering Workstation (EWS)

- Plantwide Exchange of Geometric Information (PEGI)

- Access Control and Release System (ACARS)

- Automated Engineering Change Notice

- Technical Manuals Automation

- Micro-Matic Methods Management (4M)

- Computer-Aided Process Planning (CAPP)

- PROCODE Pilots - Phase II

It should be noted that each of the above subprojects has its own set of requirements and deliverables to complete, independent of this project. This project was not intended to produce any type of production computer system. Rather, this project attempted to propose a technically feasible system flow and demonstrate the productivity improvement opportunities. In addition, concerns and problems that were encountered along the way were addressed and recommendations were made whenever possible.

Table 1 lists the team members and the Mound groups they represent. 
Table 1 - PROJECT TEAM MEMEERS

Team Members

Patrick J.' Cassidy, Project Manager Jennifer E. Andary

Richard E. Bowman

Jeffry A. Burke

Robert L. Evans

R. Keith Gwinn

Calvin A. Harper

Jeffrey A. Helgerson

Thomas W. Hughes

Finley G. Morris

Robert D. Myers

Morris Neal

R. Steven Tunning
Group

Integrated Systems Management Quality Engineering

Process Control and Data Acquisition

Product and Process Analysis

Product and Process Analysis

Communications Services

Engineering Systems and Design

Product Engineering

Operations

Engineering Systems and Design

Technical Manuals and Publications

Computer Security

Industrial Engineering

\section{Definition of Project Deliverables}

The project deliverables are described below. The team members whose names appear in parentheses have the lead responsibility for documentation.

1. Define and develop the following interfaces among the subprojects:
(A) Design Agency $\leftrightarrow \mathrm{CAD}$ (Harper)
(B) $\mathrm{CAD} \leftrightarrow$ EWS (Harper)
(C) $\mathrm{CAD} \leftrightarrow \mathrm{CAE}$ (Harper)
(D) EWS $\leftrightarrow 4 \mathrm{M}$ Database (Tunning)
(E) EWS $\leftrightarrow$ CAE (Burke)
(F) EWS $\leftrightarrow$ Technical Manuals (Myers)
(G) Technical Manuals $\rightarrow$ Shop Floor (Bowman)

2. Identify and address the following issues as related to integrating engineering applications plantwide:

(A) System incompatibilities; specifically, hardware and software (Evans via the EWS team).

(B) Communications incompatibilities (Gwinn).

(C) Security issues in general; specifically, white and blue Mound local area network (MOLAN) (Cassidy via Security subgroup). 
(D) Centralized access control to data (Cassidy, Morris, Harper).

(E) Administrative issues (all team members).

(F) Policy and procedure changes (all team members).

(G) Role/responsibility changes (all team members).

(H) System feasibility (Cassidy).

3. Demonstrate the following capabilities for unclassified portions of the MC4123 and MC4098 programs:

(A) Transmit product geometry from the design agency to the Mound computer-aided design (CAD) system via the wide band communication network (WBCN) (Helgerson).

(B) Transfer product geometry from the $\mathrm{CAD}$ system to the computer-aided engineering (CAE) system (Harper).

(C) Transfer product geometry from the CAD system to an EWS (Harper).

(D) Transmit $4 \mathrm{M}$ standards from the CAE system to the EWS (Burke).

(E) Perform CAPP functions on the EWS utilizing the $4 \mathrm{M}$ standards (Helgerson, Andary)

(F) Perform engineering analysis on the product(s) utilizing tools on both the EWS and the CAE system (Helgerson, Andary).

(G) Develop a text and graphics manual (operation sheet) on the EWS (Helgerson, Andary).

(H) Transmit the manual from the EWS to Technical Manuals and Publications (Helgerson, Andary)

(I) Transmit the finalized manual from Technical Manuals to a demonstration technical documentation database (Myers).

(J) Access the demonstration technical documentation database from the shop floor cell supervisor, retrieve the manual, and display it on a shop floor terminal (small parts worker to be determined).

\section{Deliverable No. 1: Define and Develop Interfaces Among Subprojects}

\section{Interface A: Design Agency $\leftrightarrow$ CAD}

Automated product definition exchange (APDE) is the first crucial step in achieving true computer-integrated manufacturing (CIM) at Mound and 
throughout the entire Nuclear Weapons Complex (NWC). A tactical plan was developed for standardizing product definition exchange within the NWC. Four phases are developed within the plan; each phase builds on the progress of the previous one. This plan addresses the exchange of two types of product definition information: CAD-generated drawings and documents that are pure text or a combination of text and graphics. The following sections summarize the latest draft of the proposed APDE tactical plan by phase.

\section{Phase I}

Phase I of the proposed APDE tactical plan calls for the exchange of product definition information in several forms. $\mathrm{CAD}$-generated drawings will be represented in two forms, DOEDEF and HPGL plot format. DOEDEF will provide the vehicle for exchanging two-dimensional and three-dimensional wireframe geometry and the associated drawing formats.

DOEDEF conveys information beyond that of a plot file. The electronic form supplied by DOEDEF can be taken directly into the receiving CAD system, preserving the extended information content supplied by the generating $C A D$ system. The exchange process is designed to lead users through a logical sequence of developing confidence in the DOEDEF representation through experience and enhancements to the DOEDEF software. DOEDEF is an investment that will support the exchange of more useful and accurate product definition information.

HPGL is an ASCII-based plot format used throughout the NWC. The NWC-wide common plot file format will facilitate achieving $100 \%$ visual equivalence in the exchange of $\mathrm{CAD}$-generated drawings. The plot file will serve as the electronic equivalent of the currently distributed aperture cards.

The third form of product definition will support the exchange of text only or combined text and graphics. A system developed by Pantex for documents in these forms was adopted for use by the NWC sites. It is based on the WordMARC word processing program and a set of third-party support software. During Phase I, this system will be used to create and exchange text-based documents such as product specifications.

\section{Phase II}

Phase II of the tactical plan builds upon the capabilities of Phase I and introduces the requirement that the sending site certify the DOEDEF data using common software for viewing and checking. Phase II retains the requirement for a plot file to transmit the official product definition, but no separate plot file is sent. It is generated from the DOEDEF file using an NWC-wide common plotting software package. The receiving site will create a plot directly from the DOEDEF form 
using the common plotting capability, as needed or desired. The DOEDEF file will be used further as determined by the receiving site.

Phase II will also be the point at which the enhancements developed based on the present functional objectives are introduced. The first to be introduced will likely be model/view/draw (M/V/D) and feature control blocks. Included with $M / V / D$ will be the capability to send multiple sheets per DOEDEF file.

With regard to exchanging text and graphics, the next step would be to adopt a national standard for editing or for text and graphics generation, such as SGML. As potential national standards become established, each will be reviewed for adoption by the NWC.

The interval for Phase II was chosen to coincide with the first installation of ACARS. With this event, the use of CIM 3 headers will be a requirement for all sites. At the discretion of each site, CIM 2 headers may continue to support internal needs. Common utilities to convert CIM 2 headers to CIM 3 headers and CIM 3 headers to CIM 2 headers will be provided by Los Alamos National Laboratory as NWC file utilities.

\section{Phase III}

Phase III will integrate the results of the product definition information (PDI) drafting model. It will be the first instance of an application protocol that uses the DOEDEF entity subset. The drafting model will provide the information necessary to NWC drafting and the structure to bind it together. The implementation of an NWC drafting model will improve certain conventions and practices for the use of $\mathrm{CAD}$ systems. Agreements will be needed to ensure uniformity across the complex.

The timing of Phase III is expected to provide the opportunity to upgrade the present system or procure a new system, depending on the progress made in the standards to support text generation and exchange. By Phase III, the ability to specify a common system with the capability to address the complete list of needs for document creation, editing, graphics, and exchange within the complex is expected.

\section{Phase IV}

Phase IV will involve the product data exchange specification (PDES) and its application to the data exchange needs of the complex. PDES is expected to be implemented uniformly and consistently across vendor processes, thus providing true system independence and the ability to use product definition directly (no human interpretation necessary). The effort within the NWC to influence and guide the PDES effort is crucial to achieving expectations. 


\section{Interface B: $\mathbf{C A D} \rightarrow \mathbf{E W S}$}

Currently, the CAD $\leftrightarrow$ EWS interface uses the file exchange procedure as defined by the interface $\mathrm{CAD} \leftrightarrow \mathrm{CAE}$ (see deliverable 1, interface $\mathrm{C}$ ). However, this interface will be expanded in 1989 to provide Autocad versions of BRAVO drawing databases on floppy disks, where possible, as well as on magtape. Although nọt a current production capability, this electronic form of drawing information will be available from Drawing Control. As the engineering workstations become part of the classified network and the PEGI project is implemented, file access will become electronic.

\section{Interface $\mathrm{C}: \mathrm{CAD} \leftrightarrow \mathrm{CAE}$}

The $\mathrm{CAD} \leftrightarrow \mathrm{CAE}$ interface is currently a manual exchange of files using magtape. The purpose of these exchanges is to aid in creating the CAE models by starting with Drafting's geometric product definitions. The models are necessary to perform the engineering analysis function of the $\mathrm{CAE}$ system. Magtape was selected as the method of file transfer because of two factors. The first was the difference in system classifications, which made it difficult to accomplish continuous direct connection between the two systems. The second factor was the time required to transfer such large databases using the type of connections that were available.

The transfer procedure was defined such that Drawing Control handles all file transfer requests. This procedure was originally created to allow BRAVO databases to be exchanged between the CAD and CAE systems. It has recently been used to exchange Autocad versions of BRAVO drawing component databases. The conversion between BRAVO databases and Autocad is not a production capability. However, future product geometric definition needs throughout the plant will require this conversion to become a production capability. This interface will most likely occur as the PEGI project is implemented in 1989 and 1990. It is anticipated that the CAE system will become a classified system in the same time frame.

\section{Interface D: EWS $\leftrightarrow$ 4M Database}

The 4M DATA system comprises a number of programs and associated data files written in VAX COBOL running on the user computer system (UCS) VAX 8700. This system is currently clustered with Mound's three automated office support (AOS) system processors. The 4M DATA system is a product of the Methods Time Management (MTM) Association and is an industry standard, public domain system. The primary focus of MTM is developing and maintaining accurate time standards for basic manual motions, as well as varying degrees of motion groupings, and supporting the use of these standards. 
The information developed and/or maintained on the 4M DATA system is structured by product code and operation number. The product code corresponds to Mound's product code numbering system, and the operation number is a sevendigit entry corresponding to Mound's major and detail operations. For example, product code A05689, major operation 1000, detail operation 125 in MMICS is represented as product code A05689, operation number 1000125 in the $4 \mathrm{M}$ DATA system.

For each product code and operation in the 4M DATA system, the standard labor time, standard process time (where applicable), cost center, machine and tooling information, and work analyst identification is maintained. The standard times are built from elements that can be basic MTM motions, 4M data, time studies, estimates, process times, and combinations of these. The data are developed and maintained by Industrial Engineering personnel. At the present time, the labor standards are manually transferred from the 4M DATA system to the MIMICS system, although this transaction will be automated in the future.

The engineer will access the information by opening a window during an Interleaf session and displaying the $4 \mathrm{M}$ ASCII file in this window. At that point, the user can either cut and paste the information from the ASCI file into the Interleaf document or simply rekey small amounts of new information into the appropriate area of the document. The $4 \mathrm{M}$ ASCII files reside in the $4 \mathrm{M}$ directory on the UCS. Since the UCS is accessible via white MOLAN, the user can access the 4M ASCI files through the EWS when working in Interleaf or any other engineering application.

\section{Interface E: EWS $\rightarrow$ CAE}

Table 2 shows the hardware and software required for the interface between EWS and CAE.

The engineering workstations are connected to the CAE system via the local area VAX cluster (LAVC) network. All data on the CAE system are shared throughout the entire LAVC by all engineering workstations connected to the LAVC.

CAE can be defined as any application of computer tools that facilitates the functions of an engineer and promotes CIM. Currently at Mound, CAE is typically used to analyze problems as they occur in production. This "after-the-fact" approach to problem solving is sufficient in crises, but applying CAE analyses during the design phase would avoid most of these problems. The optimal strategy is to apply CAE tools in the following areas: 


\begin{tabular}{|c|c|c|}
\hline \multicolumn{3}{|c|}{ Table 2 - REQUIREMENTS FOR EWS $\leftrightarrow$ CAE INTERFACE } \\
\hline . & EWS & CAE \\
\hline Hardware & VAXstation 2000 (or '386) & $\begin{array}{l}\text { VAX } 11 / 785 \\
\text { VAX } 8300 \\
\text { Logicraft DOS server }\end{array}$ \\
\hline Software & DECNET & $\begin{array}{l}\text { ROMULUS } \\
\text { ADAMS } \\
\text { GraFEM/IFAD } \\
\text { DYNA2D/3D } \\
\text { NIKE2D/3D } \\
\text { PRONTO2D }\end{array}$ \\
\hline Communications & $\begin{array}{l}\text { MOLAN to tech. doc. database, } \\
\text { LAVC to CAE }\end{array}$ & LAVC from EWS \\
\hline
\end{tabular}

- Design Analysis:

- Geometric Analysis

- Mechanisms Analysis

- Finite Element Analysis

- Communication

- Problem Resolution

The CAE system is chartered to directly support the CAE activities at Mound. It is the "boot node" or central controlling computer for all engineering workstations. This centralizes the system management and support activities of all engineering workstations. It also provides an integrated system for all engineering workstation users to share data throughout the network.

\section{Interface F: EWS $\leftrightarrow$ Technical Manuals}

Table 3 shows the hardware and software required for the EWS $\leftrightarrow$ Technical Manuals interface. 
Table 3 - REQUIREMENTS FOR EWS $\leftrightarrow$ TECHNICAL MANUALS INTERFACE

EWS

Hardware

Software

Communications
VAXstation 2000 (or '386)

AutoCad, MultiMate, Interleaf

MOLAN to tech. doc. database
Technical Manuals

VAXstation 2000 (or '386)

Interleaf

MOLAN from tech. doc. database

The electronic interface between the engineering workstation and Technical Manuals is fairly straightforward. The main requirement of this interface is that electronic file transfer be available for exchanging various types of text and/or graphics files. File transfer can occur by any of the following methods:

- AOS/User Library Transfer - Used to transfer text (MultiMate or ASCII) files.

- AOS Electronic Mail - Used to transfer text files.

- DECNET Copy Command - Used to transfer any file (text, AutoCad, Interleaf) from the EWS LAVC to the Technical Manuals LAVC.

In a production mode, any method of file transfer that can handle combined text and graphics files could be used on the standard EWS. This interface will always be straightforward as long as Technical Manuals uses the same type of workstation (or $100 \%$ compatible) as the engineers. Procedures will be similar to existing manual methods, but the engineers will submit documents using electronic means rather than submitting hard copies.

A logical method for complementing submissions would be to add an "electronic page" to each manual to serve as an expanded publication record. This page would carry the attribute information for the manual to which it is attached. Such information should include date of original draft (issue 1), date of submission to Technical Manuals, date of approval draft from Technical Manuals, date of acceptance by author (analogous to the original sign-off), and date of the product index $(\mathrm{PI})$.

This addendum page, which would be a permanent part of the file associated with the manual, would also serve the function of an engineering change notice/advance change order (ECN/ACO). Dates of the change notice and referenced material for the change would be indicated on the addendum page. Each iteration of the manual would be assigned the next issue number, and the previous edition could 
be archived (with a copy of the addendum sheet as it existed at that time). Details of the addendum page, file naming conventions, and screen/page format need to be worked out between Technical Manuals and Drawing Control, which would be responsible for maintaining the database from which a production worker on the shop floor would call a manual.

Changes to the existing manual would be initiated by the responsible engineer, who would submit notice to Drawing Control. This would be reflected on the addendum page and also on the PI. The requested change would then be submitted to Technical Manuals, where an editor would make the changes online and create an archive copy. Edited manuals would then be placed, by Technical Manuals, into the technical documentation database.

\section{Interface G: Technical Manuals $\rightarrow$ Shop Floor}

Table 4 shows the hardware and software requirements for the Technical Manuals $\rightarrow$ shop floor interface.

\footnotetext{
Table 4 - REQUIREMENTS FOR TECHNICAL MANUALS $\rightarrow$ SHOP FLOOR INTERFACE Technical Manuals Shop Floor

Hardware VAXstation 2000 .(or '386)

Standard shop floor workstation ( to be determined)

Software Interleaf Future Printerleaf software or To be determined custom-generated software

Communications MOLAN to tech: doc. database

MOLAN from tech. doc. database
}

Once the operation sheet has been edited and approved and is ready for release, it will be electronically sent to the technical documentation database. This database of operation sheets will most likely be located on a PROCODE VAX as Mound moves into a production mode using online operation sheets. At this point, Mound's Distributed Shop Floor Control system will electronically deliver the appropriate operation sheet to the requesting shop floor workstation. 


\section{Deliverable No. 2: Identify and Address Selected Issues as Related to Integrating Engineering Applications}

\section{System Incompatibilities}

The response time of the current engineering workstations is substandard. This is attributable in part to the LAVC in conjunction with the software. Alternative configurations are being investigated to improve the response time.

In addition, the usage of thin-wire ethernet to connect the LAVC has definite computer security implications. These concerns are expressed later in this document in the Security Issues section.

\section{Communications Incompatibilities}

MOLAN will be the backbone of all CIM activities, including those presented by this project. Currently, there are two separate MOLAN networks throughout the facility, white MOLAN and blue MOLAN. Blue MOLAN utilizes separate channels for classified and unclassified data.

The main concerns associated with communications are not technical, but rather computer security issues. For this reason, communications concerns and recommendations have been incorporated in the next section of this report, Security Issues.

\section{Security Issues}

The concern for computer security is driven by the need to protect classified information. Mound currently has over 1000 production, inspection, and testing manuals in use; $18 \%$ of the manuals are rated Confidential Restricted Data or higher. In addition, approximately $15 \%$ of all drawings used at Mound are classified.

On May 2, 1988, a temporary ad hoc team was created to address security issues pertinent to the deliverables defined by the Coordination of Engineering Applications (CEA) Project Team. The members of this subgroup are shown in Table 5.

The following sections summarize the findings of this subgroup. Additional proposals can be found in Appendix A of this document. 
Table 5 - CEA SECURITY SUBGROUP TEAM MEMBERS

Name

Group

P. J. Cassidy

C. A. Harper

C. A. Heitkamp

M. L. Neal

K. A. Weiskittle

Applied Computer \& Systems Technology

Engineering Systems and Design

Technical Security

Computer Security

Communications Services

\section{Data Classification Differences}

The data classification differences between current and planned systems are extensive. Currently, many data systems are designed only for unclassified data. This means that any similar types of data of a classified nature must be kept either on a separate, approved, secure system or, as in most cases, in a paper system. To optimize the functionality of a CIM environment, users must have access to all types of data from all computing environments. This may include accessing unclassified data on a classified system from an unclassified system or,.conversely, transferring unclassified data from an unclassified system to a classified system.

\section{Current Security Guidelines}

Security guidelines must be addressed in the design of any system that will be integrated into the PROCODE (paperless manufacturing) environment. These guidelines are intended to better reflect actual project activities leading to a computer security plan accredited by the Department of Energy/Albuquerque (DOE/AL) for the computers on which PROCODE applications will eventually run. The current security guidelines are as follows:

- A blue/white MOLAN interconnection of any type (physical, logical, electronic) is not acceptable to DOE/AL.

- The use of physically unsecured ethernet in a classified network is not acceptable.

- The methods for user identification, terminal identification, and data access protection to the file level should be incorporated concurrently such that if any of the three controls is breached, the remaining controls will sustain security protection.

- Computer security plans are written for computers intended for use in a classified or sensitive unclassified environment. The security plans require the following information: 
- Make, model, and serial number of the processor and each major piece of equipment linked to the processor. Hardware modifications and enhancements are included, whether modified by Mound or by third parties.

- List of all system software, along with a description of significant modifications. This includes detailing all security software, regardless of its source.

- Detailed descriptions of communications linkages and networks to which the processor has access.

- Detailed descriptions of the physical locations of all the principal computer system equipment. This usually includes detailed drawings of buildings, rooms, doors, alarm systems, and positions of processors and peripheral equipment that handle classified data.

- Specific statements concerning principal applications software, with detailed references to any software security enhancements.

- Statement of the authorized classification access levels for all users of the computer system. (It appears that future security plans and revisions may need to address how security will be maintained in a multilevel working - environment (i.e., personnel with $Q$ and $L$ clearances) for a specific classified computer. This has obvious implications with respect to software security and to locating and linking all classified computers.)

- Certification testing leading to $\mathrm{AL}$ accreditation for computers intended for classified or sensitive unclassified use must include a rigorous look at each of the six areas discussed above. Past experience has shown that poor planning or the lack of planning by those responsible for installation and implementation has led to the discovery, during certification testing, of significant security flaws that must be corrected prior to AL accreditation. This usually introduces time delays that generally impact implementation dates adversely.

- From the computer security perspective and, in a larger sense, from the computer services perspective, there is always a need for a clearly understood plan describing the introduction of specific VAX computers, clustered VAX computers, network linkages between these VAX systems, and any other computer systems in place or planned for the near future. This need also includes planned applications with respect to which applications will run on which computer systems, with due consideration of the classification levels at which they will run. 
Deviations from approved planning regarding harclware, software, locations, clustering, and linkages will usually introduce delays into the normal AL approval cycle leading to accreditation for classified use.

\section{Centralized Access Control to Data}

\section{External ACARS}

ACARS is a document management system that will be installed at each site in the NWC. ACARS is a common software system that automates the distribution, control, and management of product definition documents electronically within the NWC. ACARS contains features such as access controls, document management, intersite document transfer, and document distribution.

ACARS is layered upon Cullinet's database management system, IDMS/R. IDMS/R runs on an IBM mainframe under the MVS operating system. Security is enforced by a software package similar to resource access control facility (RACF).

ACARS manages documents that reside on the common file system (CFS). Documents are combined with data describing the document and stored in the form of NWC files through the use of the CIM file header tools and utilities. ACARS transmits documents between. NWC sites via the WBCN. ACARS interacts with the WBCN by using the WBCN worker services.

The ACARS user community encompasses designers, engineers, managers, classifiers, and clerks. Each site will tailor ACARS according to the job responsibilities at the site and the business practices by which the site exchanges product definition data with its business partners.

\section{Internal ACARS}

Change procedures for the following product definition elements (PDEs) will be defined and administered by Engineering Systems Design (ESD):

- Drawings

- Material Lists

- Specifications and Procedures

- ECNs and ACOs

- Manuals

- Operation Sheets

- Product Indexes

- Bills of Materials

- Routings 
The ESD group is responsible for establishing and administering policies and procedures for making changes to the PDEs listed above. The authorized engineer is responsible for effecting the changes. The access, control, and release software and associated files will be managed from a single, plantwide, application processor.

Portions of this access, control, and release software and data may be downloaded to other plantwide application processors to facilitate user access to PDEs stored there. Distributive processing and distributive database management techniques are not yet robust and reliable enough to commit to use in a production environment.

Specific PDEs will be stored on the plantwide application processor with primary responsibility for processing those PDEs. PDE data will be distributed from the plantwide application processor on which they reside. The CFS will be used for archival and backup purposes, as well as for file-to-file transfer among plantwide application processors.

Mound will establish at least two file formats in addition to the native Bravo format. All new drawings or frequently requested drawings will be maintained in a neutral format, perhaps a modified IGES format, and a view-only format, perhaps HPGL. It is necessary to establish guidelines in these areas to achieve a responsive, production capability for distributing electronic geometries. Additionally, post-processing software to translate the neutral file to AUTOCAD, ORCAD \& REGIS will be provided for use at either the host or the EWS level, or both. This process should support bidirectional flow.

The consolidation of the existing CAD System Management and Operations group and personnel into Computer Services would facilitate establishment of the OSW third-floor $\mathrm{CAD}$ computing resource as a plantwide data center. Economy in space, operations, maintenance, planning, management, equipment, and support would result.

The following list identifies the functions of each of Mound's major computer resources:

- CAD - Support of the Design Drafting function, numerical control, and internal and external translation.

- CFS - Archival and backup storage. File-to-file transfer for plantwide application processors. 
- PCS - Production Computer System. Administrative and financial systems; possibly production planning and control (manufacturing resources planning (MRP) II).

- UCS - Unclassified system to support ad hoc query of production data (not updating of data).

- PROCODE - Production data acquisition (distributed shop floor control, or DSFC), CAPP, and possibly production planning and control (MRP II).

- CAE - Engineering analyses system.

Although these represent the primary functions of various systems, the possibility of clustering where feasible and beneficial will be considered when determining how systems such as PCC and PROCODE will be implemented.

\section{Administrative Issues}

Key customer requirements include shorter design-to-manufacturing times, reduced product cost, improved quality and reliability, and timely response to dynamic production and surveillance schedules. To satisfy these key requirements, Mound must change the way it does business.

A need exists to develop a plantwide integrated manufacturing system at Mound. A clear understanding of global manufacturing goals must be developed. Industrial Engineering should review each production area to ensure a simplified process before integration into the plantwide system. Eliminating the use of the many islands of automation will enable the site to realize the productivity improvements. The biggest concern in interdepartmental integration is having all departments actively participate in implementing the paperless manufacturing system.

The integrated manufacturing system must be flexible, expandable, and modifiable; it must retrieve data easily and must provide Mound with the ability to manage change. It must allow real-time management, and it must collect product and process data in realtime. The system must also be user-friendly, as defined by the users, which means that it must be adaptable to specific user requirements. The system must be capable of being piloted at all levels. Real-time process control must be put into the hands of the users. Input of product specification data into the system must be required. Real-time, online product specifications, drawings, and procedures are musts. The system must enable the users to create management reports while providing the necessary technical tools to get the job done. The system must interact with Mound's drawing control system. 
Time spent on the system reporting activities must be productive. Data input must satisfy DOE/AL and design agency requirements. All the hardware and software must be compatible. The total cost of the system must be identified. Problem feedback to the operator is required. Written procedures must be eliminated; the system must aid in increasing Mound's quality by providing real-time input on quality problems. The system must provide process controls while providing statistical process control and statistically significant data, be able to process classified information, and be designed to enable interaction with future automation. The control of access to production data is required. The system must provide production controls and must provide the ability to support CAPP and capacity planning.

It is desired that the system be closed looped and auditable and that it provide production and cost of scrap information. The system should also increase productivity, decrease product cost, tie into the finance system, and meet DOE needs. It should replace previous systems and reduce administrative costs associated with running them. The system should be compatible with Mound's product definition and $\mathrm{CAD}$ functions and provide efficiency data. It should be plantwide, cover the total scope of work at the plant, and possibly aid in generating budget data.

\section{Policy and Procedure Changes}

Mound's existing systems were developed as standalone systems because related systems either did not exist or were on incompatible hardware. As new systems were added, it was not always possible to integrate them with the old. Therefore, plantwide system requirements were not incorporated into the system design. Many systems share the same information while using different naming conventions to identify and store it. There is a need to continue the good elements of each system, to fix the poor elements of each system, and to improve on all areas to meet user needs.

\section{Role/Responsibility Changes}

The many productivity improvements listed above are directed at simplifying and integrating the way Mound employees work. Each of the improvements will effect changes throughout the plant. Along with the changes will come new roles and responsibilities. This project alone will not correct production workflow unless Operations applies industrial engineering and process engineering principles to existing processes before they are moved into the paperless manufacturing system.

Implementation of the organizational changes should occur concurrently with necessary systems training. Areas requiring training are MRP II, CAPP, and 
DSFC. Management must enforce system discipline once the system is in place and must ensure new islands of automation do not emerge after implementation.

\section{System Feasibility}

All interfaces examined in deliverable no. 1 are technically feasible. In many cases, there are several methods available to perform a given function. In these cases, the most pressing question to ask is "Which system will be most compatible when integrated with other systems in Mound's CIM environment?"

Fully functional CIM systems have been implemented in various plant sites throughout the world; some have been successful, while others have failed. The technology is available, but integration into one working environment is the key issue in implementing CIM successfully.

\section{Deliverable No. 3: Demonstrate Selected Capabilities for Unclassified Portions of the MC4123 and MC4098 Programs}

The capabilities to be demonstrated for unclassified portions of the MC4123 and MC4098 programs include the following:

1. Transmit product geometry from the design agency to the Mound CAD system via the WBCN.

2. Transfer product geometry from the $\mathrm{CAD}$ system to CAE system.

3. Transfer product geometry from the CAD system to an EWS

4. Transmit $4 \mathrm{M}$ standards from the CAE system to the EWS.

Since the development of these project deliverables, the $4 \mathrm{M}$ system has been moved from the CAE system to the UCS.

5. Perform CAPP functions on the EWS utilizing the $4 \mathrm{M}$ standards.

For the CEA demonstration, an ASCII file was produced for each required product through a $4 \mathrm{M} / \mathrm{VAX}$ utility function. This file contains the following data for each operation in the specified product code:

- Product Code

- Product Description

- Operation Number

- Operation Description

- Standard Time 
6. Perform engineering analysis on the product(s) utilizing tools on both the EWS and the CAE system.

7. Develop a text and graphics manual (operation sheet) on the EWS.

8. Transmit the manual from an EWS to Technical Manuals.

9. Transmit the finalized manual from Technical Manuals to a demonstration technical documentation database.

10. Access the demonstration technical documentation database from the shop floor cell supervisor, retrieve the manual, and display it on a shop floor terminal.

The above capabilities were successfully demonstrated on December 1, 1988. Comments and concerns received from the attendees of the demonstration have been addressed in this document.

\section{Related Documents}

The following is a list of documents that were used as references in creating this document or that contain additional information pertinent to engineering applications or integration into paperless manufacturing.

- Computer-Aided Process Planning Requirements Document.

- Distributed Shop Floor Control Requirements Document.

- MRP II Requirement Document.

- Paperless Manufacturing Information and Control System Document.

- ADPE Tactical Plan.

- Computer-Aided Engineering Newsletter, November 1988.

- ACARS Deliverables and Requirements Document. 
22 


\section{Appendix A \\ Computer Security Proposals}

The following proposals are submitted to meet the general security requirements needed for PROCODE (paperless manufacturing).

\section{VAXCluster Security Environment Proposal}

The VAXCluster environment diagram (Figure A-1) shows the example configuration that is discussed in this appendix. White MOLAN or any unclassified communication lines can be connected to VAX 4, VAX 5, or both. Blue MOLAN or any secured line can be connected to either VAX 6, VAX 7, or both. VAX 4 and VAX 5 are connected together by an ethernet, as are VAX 6 and VAX 7. However, the subnet for VAX 4 and 5 is isolated from the subnet for VAX 6 and 7. The VAXs access the disk drives by way of the star coupler (SC) and the high-speed controllers (HSCs). The SC is a passive device. The HSC is a high speed disk and tape controller. It has its own operating system. There is no capability to add any user written code to the HSC system. By convention, unclassified data and classified data are segregated onto individual disk drives. The cables connecting the VAXs to the HSCs are connected by way of a computer board in the VAX called a CI. This CI board determines whether communications from the HSC are for this VAX. Until the $\mathrm{CI}$ verifies the communication for this VAX, it is not moved into the system where it is first accessible. No capability exists from the VAX system to interrogate the data that transfers on these cables.

The HSC has a user interface that handles to configuration generation. The required HSC settings are set to allow access to any of the unclassified data disks and to deny. VAX 4 and VAX 5 access to the classified data disks. Configuration changes require the HSC to be rebooted before the changes take effect. Access to change the HSC from any account on the VAX, including the SYSTEM account, is not possible when the HSC SECURE/ENABLE switch is in the SECURE position.

\section{Engineering Workstation Configuration Proposal}

The following proposal will allow Mound to implement the EWS in a classified environment without a great deal of replanning or expense.

The EWS is configured as a VAXstation 2000 with a fixed disk. There are no floppies or removable disk units connected to the EWS. The fixed disk contains no data and no structure as yet. 


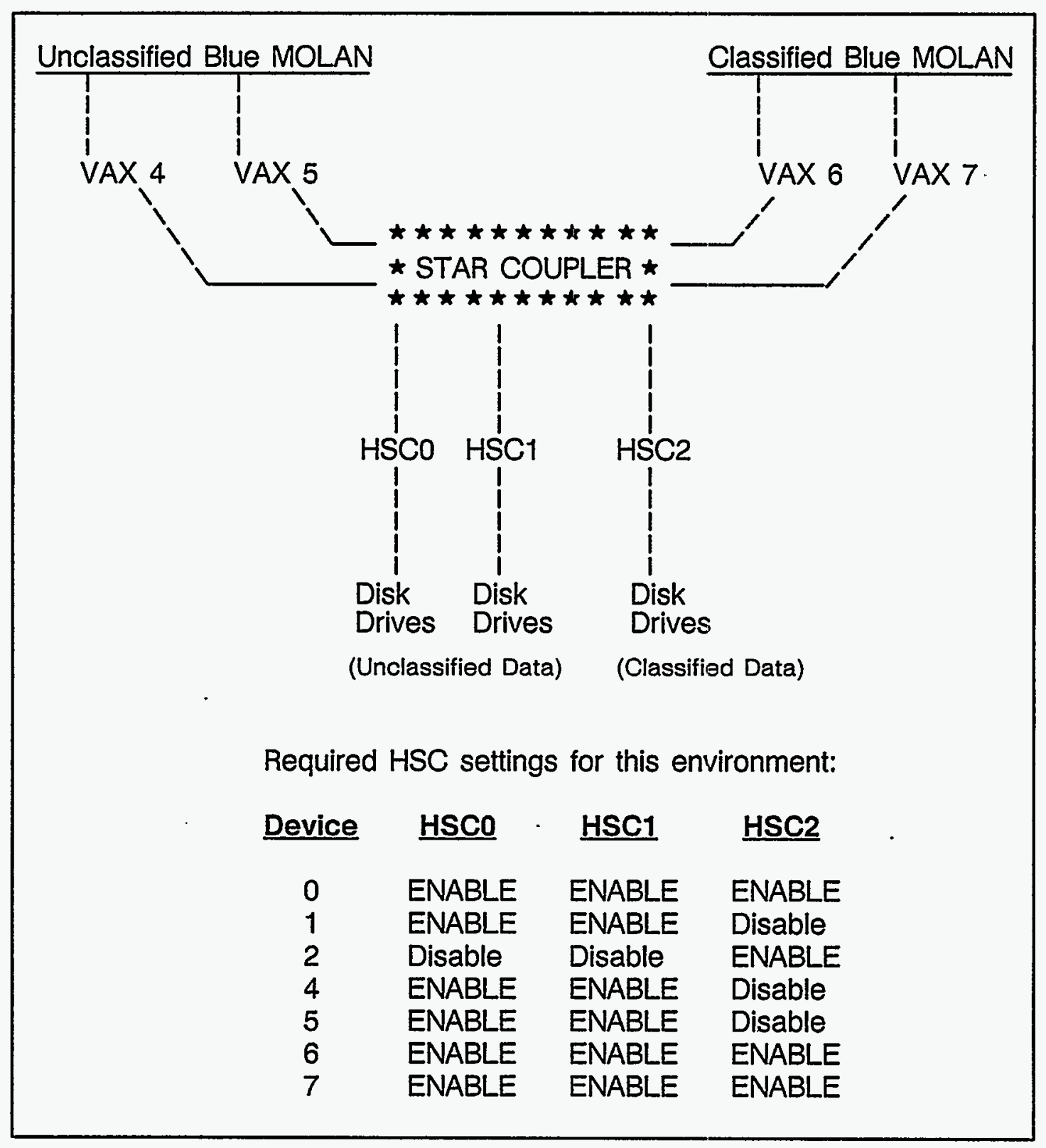

Figure A-1 - VAXCluster environment.

The user will connect his EWS through MOLAN to the LAVC boot node. The LAVC will boot the EWS and download a tailored version of MicroVMS. It will then reboot the EWS as a local standalone workstation. At this point the EWS is independent of the LAVC and can be considered a standalone system.

The tailored version of MicroVMS will be configured specifically for each EWS user by operations. Several features of this tailored version are worth mentioning: 
- The user will be working from a captive account with only the necessary privileges needed to perform his job function.

- If the user is approved for classified processing, he will have two captive accounts as part of the tailored MicroVMS; one will be for unclassified processing and the other for classified processing. Using MicroVMS security protections, the classified account would be able to access the directory structure to be used for temporary classified files and processing. The unclassified account will not have such access.

- System processes will be running as part of the MicroVMS environment that will verify the EWS configuration and classification status before the user is allowed to $\log$ on the EWS and during work processing. The user will not be able to alter this or any system processes.

- File system security mechanisms will protect classified files from being copied to the co-resident unclassified directory structures on the VAXstation 2000.

As a standalone system, the EWS can be connected to white MOLAN and use the unclassified account on the EWS to perform AOS type processing. Another unclassified host will be available to store the user's unclassified EWS files. The EWS can be connected to blue MOLAN and use the classified account on the EWS to access classified documents or files. The classified host will log all files copied to the EWS. Also, the host will have software that will periodically ensure the files still exist on the EWS and the EWS is still connected properly. Any abnormalities will result in an operator alarm being triggered on the classified host's console, and the appropriate action can be taken. As part of the MicroVMS log off software, files in the classified directory structure will be loaded back to the classified host. The tailored MicroVMS will then erase all files from the classified directory structure. Approved procedures for erasing classified files from the hard disk to sanitize the disk will be used.

The classified host will expect successful "disk sanitized" messages before the log off can be completed. Otherwise, an operator alarm will be triggered on the classified host's console. After the EWS is sanitized, it will be an unclassified standalone system again.

The following list describes the advantages of this approach:

- Allows all goals of the EWS effort to continue to be met.

- Makes EWS a standalone system that could require only local computer security approval for classified processing (similar to a PC).

- Reduces the risk of the insider threat by securing the operating environment, providing no local removable media, and logging all files accessed. 
- Provides the least expensive alternative for EWS to be approved for classified processing.

- Requires a shorter time to implement EWS in a classified environment.

- Allows all system software to be controlled and loaded from operations CPU.

- Requires operations support to implement user hardware configuration changes.

The following list describes the disadvantages of this approach:

- Part of the EWS hard disk storage is used for the tailored MicroVMS.

- Licensing of the MicroVMS is required for each EWS.

- Only VAXstations can process classified data because of security protection of MicroVMS.

- No local removable media, such as floppies and removable disks, are allowed.

\section{Security Plan Proposal}

The CEA Security subgroup makes the following recommendations for a "non-tradition," plantwide three-level security plan:

\section{Level 1 Plan}

The level 1 plan would be a single plant plan that defines high-level mission statements and plantwide "visions" of Mound's manufacturing environment. It would include a generic description of how Mound's computer architecture is structured, controlled, and integrated and would be open ended. This level 1 plan would not normally change on a regular basis. The main areas of discussion would most likely be as follows:

- Overview of the PROCODE (paperless manufacturing) environment.

- Description of Mound's distributed architecture.

- Description of the functionality of MOLAN.

- Description of Mound's implementation of an internal ACARS.

\section{Level 2 Plan}

The level 2 plan would comprise a detailed series of "annexes" (or chapters) to the level 1 plan. These would be descriptions of larger systems (e.g., CAD, PCS, CFS, WBCN, MOLAN, UCS, AOS).

Initially, existing approved security plans for these larger systems would simply be annexed to the level 1 plan "as is." As these plans are required to be updated 
(normally every 12 months), they would be stripped of generic information already existing in the level 1 plan. In a similar manner, a list of input/output (I/O) devices integrated into this system would be segregated into a corresponding level 3 plan.

\section{Level 3 Plan}

The level 3 plan would consist of a simple list of $\mathrm{V} / \mathrm{O}$ devices that are connected to or integrated with the larger systems. This might be nothing more than a description of equipment, its location, and the person responsible.

\section{Benefits}

The benefits of a three-level security plan include the following:

- The generic information normally included in all existing security plans would no longer need to be repeated in new security plans. This information would always reside in the plantwide level 1 plan. This will drastically reduce the amount of time it takes to develop new security plans.

- Since generic information always resides in the level 1 plan, multiple updates to level 2 security plans would not be required because of changes to the level 1 plan. These high-level changes would need to be made only once in the level 1 plan.

- Changes to system configurations would not require an update to the level 2 security plan. These changes or additions would simply be made to the corresponding level 3 plan, which could be approved at Mound locally by Computer Security.

- As a result of this three-level design, level 2 security plans would be drastically reduced in size. This in turn will most likely reduce the amount of time it takes to get the security plan through the approval processes both internally and externally. 


\section{Distribution}

\section{EXTERNAL}

J. A. Morley, DOE/DAO

\section{INTERNAL}

J. E. Andary

D. B. Armstrong

D. L. Badgley

P. D. Bantz

R. E. Bowman

D. P. Branscomb

T. M. Bruggeman

J. A. Burke

S. M. Casbeer

P. J. Cassidy (5)

V. E. Castleberry

D. B. Chambers

A. F. Ciramella

R. C. D'Amico

E. G. Depew

G. E. Early

E. C. Eimutis

R. L. Evans

R. A. Fischbein

A. L. Goldman

R. K Gwinn

C. A. Harper

J. D. Hastings

J. A. Helgerson

D. R. Hill

E. D. Hill

A. J. Hodapp

T. W. Hughes

C. W. Huntington

J. A. Jackson

R. A. Johnson

T. Z. Jones

L. J. Karnowski

D. P. Kelly
F. D. Lonadier

R. F. Lowrey

J. F. Madden

J. J. Maher

L. R. McCabe

D. L. Michaels

D. E. Michel

S. L. Miller

F. G. Morris

G. L. Morris

R. D. Myers

M. L. Neal

W. S. Nissen

S. L. Nowka

G. L. Numbers

M. R. Phillips

M. S. Sizemore

W. H. Smith

M. J. Stanoikovich

B. M. Stewart

D. H. Stitzel II

R. S. Tunning

R. E. Vallee

E. M. Warmoth

K. A. Weiskittle

F. W. Weyler

B. D. Wheeler

H. A. Woltermann

W. C. Wyder

J. R. Wysong

W. Yurkowsky, Jr.

Publications

Document Control (3) 